\title{
The low temperature crystalline and glassy states of methyl $\alpha$-hydroxy-isobutyrate $\dagger$
}

\author{
Susana Jarmelo, Teresa M. R. Maria, Maria Luísa P. Leitão and Rui Fausto* $\ddagger$ \\ Departamento de Química, Universidade de Coimbra, P-3049 Coimbra, Portugal. \\ E-mail:RFausto@ci.uc.pt
}

Received 22nd September 2000, Accepted 30th November 2000

First published as an Advance Article on the web 15th January 2001

\begin{abstract}
The low temperature crystalline and glassy phases of methyl $\alpha$-hydroxy-isobutyrate (MHib) were identified and characterized structurally by differential scanning calorimetry, IR and Raman spectroscopy and molecular modeling. Within the temperature range $13-171 \mathrm{~K}$, MHib exists as a glassy state, where individual molecules may assume the two conformational states previously observed for this compound isolated in an argon matrix and in the liquid phase [S. Jarmelo and R. Fausto, J. Mol. Struct., 1999, 509, 193]. At ca. 171 K, devitrification occurs and a crystalline phase may then be formed [ $T$ (onset) $\approx 213 \mathrm{~K}$ ], the enthalpy of crystallization being $c a .5 \mathrm{~kJ} \mathrm{~mol}^{-1}$. The crystalline phase was found to exhibit conformational selectivity-in this phase all individual molecules assume a conformation analogous to the most stable conformer found for the isolated molecule and in the liquid (the Syn-syn s-cis conformer, where the $\mathrm{H}-\mathrm{O}-\mathrm{C}-\mathrm{C}, \mathrm{O}-\mathrm{C}-\mathrm{C}=\mathrm{O}$ and $\mathrm{O}=\mathrm{C}-\mathrm{O}-\mathrm{C}$ dihedrals are $c a .0^{\circ}$ ). Molecular modeling and Raman data are consistent with a structural unit within the crystal where two MHib molecules form a centrosymmetrical hydrogen bonded dimer. The observed temperature of fusion $\left[T_{\mathrm{f}}(\right.$ peak $\left.)\right]$ for the crystal is $240 \mathrm{~K}$.
\end{abstract}

\section{Introduction}

In the last few years, $\alpha$-hydroxy-substituted carboxylic compounds have interested many people due to their important medical and pharmaceutical applications. ${ }^{1-4}$ The use of $\alpha$ hydroxy-substituted carboxylic compounds in dermatology and the cosmetics industry is well known, ${ }^{1,2}$ but these substances are also currently used as inhibitors of harmful oxidation biochemical processes ${ }^{3}$ and important research is presently going on in order to develop new materials based on biodegradable polymers derived from these compounds that can be used for reconstruction of biological tissues and in organ transplantation. ${ }^{5}$ In addition, these molecules also play an important role as precursors of polymeric materials currently used for different applications. ${ }^{6}$

Very recently, we have undertaken a detailed structural and spectroscopic study of the low temperature phases of methyl glycolate $\left(\mathrm{CH}_{2} \mathrm{OHCOOCH}_{3}\right){ }^{7}$ the smallest member of the family of $\alpha$-hydroxy esters. As a starting point to interpret the experimental data for the condensed phases we used the information previously obtained for monomeric methyl glycolate by matrix-isolation IR spectroscopy and quantum chemical calculations. ${ }^{8}$ We have found that, within the temperature range $13-273 \mathrm{~K}$, methyl glycolate may exist in three solid phases: a glassy state, existing at the lowest temperatures $(<174 \mathrm{~K})$, and two crystalline phases - a stable crystalline phase, which can be formed from the liquid upon slow cooling or by heating the completely vitrified sample, and a metastable crystalline variety, which can be obtained by heating a sample previously cooled from the liquid using higher cooling rates $\left(v_{\text {cooling }} \geqslant 10 \mathrm{~K} \mathrm{~min}^{-1}\right){ }^{7}$ The stable crystalline phase of methyl glycolate was found to exhibit conformational selectivity, all individual molecules assuming a conformation similar to the most stable conformer found for the isolated

$\dagger$ Electronic Supplementary Information available. See http:// www.rsc.org/suppdata/cp/b0/b007722o/

† URL: http://www.qui.uc.pt/ rfausto/homepage molecule, ${ }^{8}$ with two non-equivalent molecules in the crystal unit cell. ${ }^{7}$

To the best of our knowledge MHib has not yet been the subject of any experimental or theoretical spectroscopic or structural study in the condensed phases. On the other hand, this compound was also studied in our previous matrixisolation spectroscopic and quantum chemical study, ${ }^{8}$ where the preferred conformations assumed by its monomer could be well established. Indeed, as methyl glycolate, MHib exists in two experimentally detectable conformational states in the isolated molecule situation: the Syn-syn s-cis conformer (Ss; see Fig. 1), which exhibits an intramolecular $\mathrm{OH} \cdots \mathrm{O}=\mathrm{C}$ hydrogen bond and is the most stable form, and the doubly degenerated by symmetry Gauche-skew s-cis conformer (Gsk; dihedral angles $\mathrm{H}-\mathrm{O}-\mathrm{C}-\mathrm{C}, \mathrm{O}-\mathrm{C}-\mathrm{C}=\mathrm{O}$ and $\mathrm{O}=\mathrm{C}-\mathrm{O}-\mathrm{C}$ of $49.4^{\circ}, 148.3^{\circ}$ and $-0.9^{\circ}$, respectively, see also Fig. 1) which has an energy $6.6 \mathrm{~kJ} \mathrm{~mol}^{-1}$ higher than the conformational ground state, in the gaseous phase. ${ }^{8}$

In the present study, structural, thermodynamic and vibrational data for the solid phases and phase transitions of MHib within the temperature range $13-273 \mathrm{~K}$ are reported. Differential scanning calorimetry was used to detect and characterize low temperature phase transitions and vibrational spectroscopy (both Raman and IR) was used to shed light on the nature of the different phases observed. Theoretical results

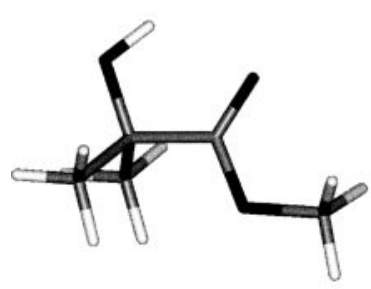

Syn-syn-s-cis

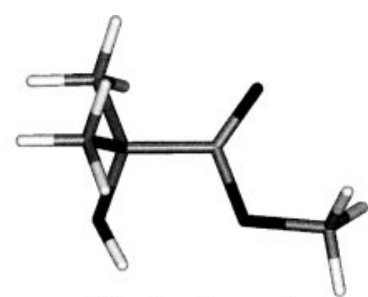

Gauche-skew-s-cis $\Delta E=6.6 \mathrm{~kJ} \mathrm{~mol}^{-1}$
Fig. 1 Most stable conformers of methyl $\alpha$-hydroxy-isobutyrate. 
obtained from quantum chemical calculations ${ }^{8}$ or from molecular modeling were used to aid interpretation of the vibrational data and to characterize the main intermolecular interactions present in the crystalline phase.

\section{Experimental}

Methyl $\alpha$-hydroxy-isobutyrate was commercial spectroscopic grade and used without any additional purification.

IR spectra were obtained using a Mattson (Infinity Series) Fourier-transform spectrometer equipped with a deuterated triglycine sulfide (DTGS) detector and $\mathrm{Ge} / \mathrm{KBr}$ optics. Data collection was performed with $1 \mathrm{~cm}^{-1}$ spectral resolution. The solid state samples were prepared as a thin film by spraying the necessary amount of vapor of MHib, previously contained in an air-purged glass tube which was directly connected to the cryostat by a flux controlling valve, onto a $\mathrm{KBr}$ window cooled using an APD cryogenics DMX closed cycle helium refrigeration system whose principal component is a DE-202 Displex expander. The refrigeration system is supported by an APD cryogenics Helium compressor (model HC-2D-1) and is connected to a high efficiency vacuum system whose main component is an Alcatel PTR5001 turbomolecular pump. The deposition temperature, measured at the window with a Silicon diode sensor and a Scientific Instruments digital temperature controller (model 9650), was $13 \mathrm{~K}$. The error in temperature measurements was less than $0.5 \mathrm{~K}$.

Raman spectra were obtained using a SPEX 1403 double monochromator spectrometer (focal distance $0.85 \mathrm{~m}$, aperture $f / 7.8$ ), equipped with holographic gratings with 1800 grooves $\mathrm{mm}^{-1}$ (ref. 1800-1SHD). The $514.5 \mathrm{~nm}$ argon laser (SpectraPhysics, model 164-05) line, adjusted to provide $220 \mathrm{~mW}$ power at the sample, was used as excitation radiation. Detection was effected using a thermoelectrically cooled Hamamatsu R928 photomultiplier. Spectra were recorded using increments of $1 \mathrm{~cm}^{-1}$ and integration times of $1 \mathrm{~s}$. The sample was sealed into a glass capillary tube, which is inserted within a Harney-Miller cell. ${ }^{9}$ The cell was then cooled using a continuous flux liquid nitrogen refrigeration system equipped with an Alcon electrovalve (model 68252412) that enables a precise control of the nitrogen flux reaching the cell. Temperature is controlled by a T48 (Red Lion Controls) temperature controller, the experimental error in the measured temperature being $c a .1-2 \mathrm{~K}$ within the range of temperatures covered.

Thermal studies were carried out with a Perkin-Elmer differential scanning calorimeter (Pyris-1), over the temperature range $113-283 \mathrm{~K}$. Scanning rates ranging from 2 to $10 \mathrm{~K}$ $\min ^{-1}$ were used. For cooling, the Perkin-Elmer liquid nitrogen cooling system CryoFill-1 was used. The samples (2-4 mg) were pressed in aluminium pans suitable for volatile substances. Temperature calibration was performed between 113 and $283 \mathrm{~K}$ with high-grade cyclopentane and cyclohexane (Merck; reference substances for gas chromatography) and ndecane (Sigma, 99+\%). For heat calibration, the enthalpy of the solid-solid transition of cyclohexane occurring at 186.25 $\mathrm{K}^{10}$ was used.

Molecular modeling studies were undertaken with the CFF95 force field ${ }^{11}$ and the Cerius ${ }^{2}$ (version 3.5) molecular modeling package ${ }^{12}$ using the program standard convergence criteria and optimization algorithms.

\section{Results and discussion}

\subsection{Differential scanning calorimetry (DSC) studies}

Fig. 2 summarizes the DSC results obtained for MHib. The curves correspond to four successive cycles where both cooling and heating rates were kept equal to $10 \mathrm{~K} \mathrm{~min}^{-1}$.

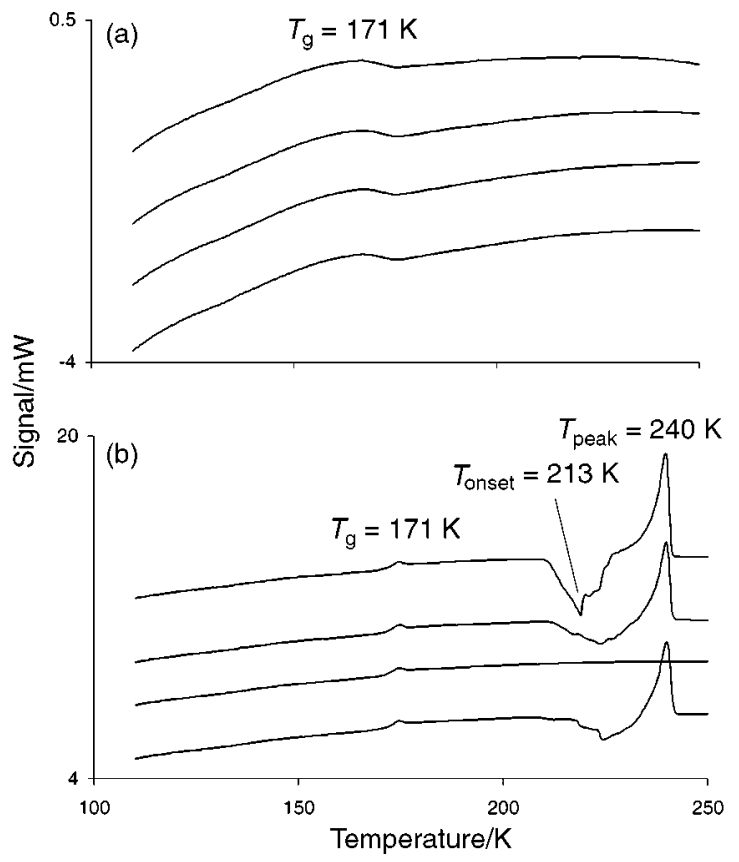

Fig. 2 DSC (a) cooling and (b) heating curves of a sample of methyl $\alpha$-hydroxy-isobutyrate (four successive cycles are shown). $T$ corresponds to the peak temperature associated with fusion; $T^{\prime}$ is the temperature of the peak associated with crystallization.

Similar results were obtained using other cooling or heating rates.

For the sample shown as on example in the figure, the cooling curves corresponding to the various cycles are essentially equal, showing a noticeable change of heat capacity and absence of any feature ascribable to a crystallization, thus clearly indicating that the sample completely vitrifies upon cooling.

The heating curves show a more complex pattern of variation. Besides the glass transition at $c a .171 \mathrm{~K}$, the curves corresponding to the two first cycles as well as that associated with the fourth cycle present a complex exothermic peak with an onset temperature of $c a .213 \mathrm{~K}$, which corresponds to the formation of a crystalline phase $\left(\Delta H_{\text {cryst }} \approx 5 \mathrm{~kJ} \mathrm{~mol}^{-1}\right)$, immediately followed by an endothermic peak $\left(T_{\text {peak }} \approx 240 \mathrm{~K}\right)$ associated with the fusion of the crystal. The glass transition occurs with a small positive enthalpy change, which appears superimposed with the change of heat capacity, revealing that some structural relaxation occurs during devitrification. This phenomenon has been previously observed for other systems, in particular for methyl glycolate. ${ }^{7,13-15}$ The complex structure exhibited by the crystallization peak indicates that this transition is a multi-step process. This is a common situation for organic molecules where hydrogen bonding interactions play important structural roles and was also observed previously for methyl glycolate. ${ }^{7,13}$ As will be stressed later, in the case of MHib, crystallization requires conformational reorganization and intermolecular $\mathrm{H}$-bond formation, besides quenching of translational and rotational degrees of freedom.

Very interestingly, despite the fact that all the controllable experimental conditions used were the same in all cycles (in particular the heating and cooling rates), the heating curve corresponding to the third cycle (see Fig. 2) shows only the feature corresponding to the glass transition, near $171 \mathrm{~K}$, clearly indicating that no crystallization and subsequent crystal fusion occurred then for this particular sample. Similar behavior was systematically observed for all samples subjected to DSC studies, though the absence of the crystallization and fusion peaks does not seem to follow any recognizable pattern with respect to the particular cycle in which it occurs. So, this 
apparent random absence of crystal formation during successive thermodynamic cycles must be related to very subtle factors acting on nucleation, which are experimentally inaccessible.

\subsection{Vibrational spectroscopy (IR and Raman) and molecular modeling studies}

Our previous combined vibrational spectroscopic and $a b$ initio quantum chemical study on MHib provided a detailed understanding of the vibrational signature of the two conformers of this molecule that are experimentally observed for the isolated molecule situation as well as in the liquid phase (conformers Ss and Gsk, see Fig. 1). ${ }^{8}$ Marker bands due to the individual conformers could then be identified and can be used as probes to look for their presence under different experimental conditions. The bands ascribed to the $\delta \mathrm{O}=\mathrm{C}-\mathrm{O}$ and $\delta \mathrm{C}-\mathrm{C}=\mathrm{O}$ bending modes are particularly suitable, since the two conformers give rise to relatively intense and well separated bands occurring in clean spectral regions $(\delta \mathrm{O}=\mathrm{C}-\mathrm{O}$ : Ss, $613 \mathrm{~cm}^{-1}$; Gsk, $598 \mathrm{~cm}^{-1}$; $\delta \mathrm{C}-\mathrm{C}=\mathrm{O}$ : Ss, $475 \mathrm{~cm}^{-1}$; Gsk, $504 \mathrm{~cm}^{-18}$ ).

The present study deals essentially with the solid state, where molecular aggregates and intermolecular interactions are expected to play important roles. For this kind of system, the available quantum chemical methods that can provide reliable theoretical grounds for the interpretation of the observed spectroscopic data are still prohibitive in terms of computational needs. In these cases, classical molecular modeling methods (molecular mechanics) constitute a suitable alternative, which has been extensively tested. ${ }^{16-19}$ In this study, the second generation CFF95 force field of Hagler and coworkers ${ }^{11}$ was used to perform the molecular modeling calculations, since this force field was shown to yield molecular geometries and vibrational data for methyl glycolate in good agreement with the experimental data. ${ }^{7}$

Table 1 compares the vibrational results obtained using CFF95 for the conformational ground state of monomeric MHib (conformer Ss) with both experimental (matrix isolation; IR) and ab initio $\mathrm{HF} / 6-31 \mathrm{G}^{*}$ (scaled values) data. ${ }^{8}$ As expected, the general agreement between the CFF95 and the experimental results is fairly good; with a few exceptions, the correction factors to the calculated values, defined as $\left(v_{\text {exp }}-v_{\text {CFF95 }}\right)$, are less than $5 \%$ of the experimental value, the average absolute value being $45.6 \mathrm{~cm}^{-1}\left(38 \mathrm{~cm}^{-1}\right.$ if the two largest correction factors were excluded).

Fig. 3 and 4 show the experimental spectra obtained for both the glassy and crystalline states of MHib. These spectra are compared with the room temperature liquid phase spectra. The CFF95 predicted Raman spectrum for the crystalline phase is also shown in Fig. 4 (details of calculation will be provided later). Band assignments are given as Electronic Supplementary Information. $\dagger$

In the temperature variation Raman studies, the sample initially at room temperature was cooled to $77 \mathrm{~K}$ and subsequently rewarmed to room temperature. All spectra obtained at stationary temperatures during the cooling are similar, though the usual band narrowing effect due to decreasing temperature could be easily noticed and some minor changes in relative intensities due to changes in the intrinsic intensities with temperature could also be observed (see Fig. 3). This is a clear indication that the general structure of the liquid is preserved upon solidification as could be expected taking into consideration the DSC data that indicates that upon cooling MHib forms a glassy state. In the glassy state spectra, marker bands of both Ss and Gsk conformers are easily observable, showing that in this phase MHib individual molecules may assume the two conformational states previously observed for this compound isolated in an argon matrix and in the room temperature liquid phase. ${ }^{7}$ On the other hand, upon warming,
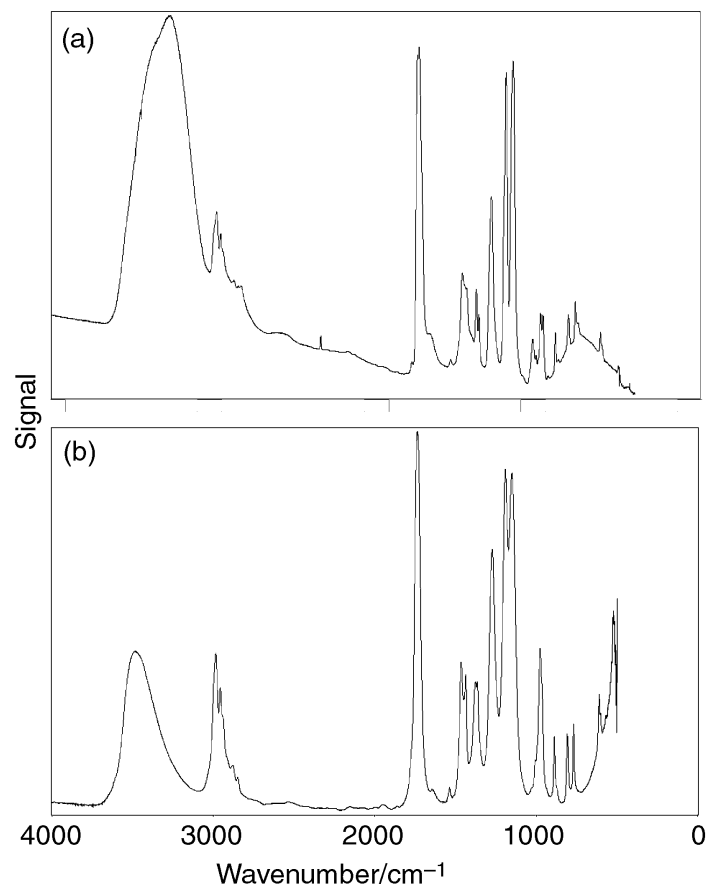

Fig. 3 IR spectra of methyl $\alpha$-hydroxy-isobutyrate. (a) Glassy state $(T=119 \mathrm{~K})$ and $(\mathrm{b})$ liquid $(T=298 \mathrm{~K})$.

a noticeable change in the spectrum may occur at the temperature where the crystalline phase is expected to be formed (ca. $213 \mathrm{~K}$ ). Note that the Raman experiments fully support the DSC observation that the crystalline phase is not always formed. By comparing the Raman spectra of the crystal with those of the liquid and glassy states, it is clear that those bands due to the higher energy form Gsk are absent in the spectrum of the crystal. So, as was previously found for methyl glycolate, ${ }^{7}$ the crystalline phase of MHib exhibits conformational selectivity - in this phase, all individual molecules assume a conformation analogous to the most stable conformer found for the isolated molecule and in the liquid (Ss form).

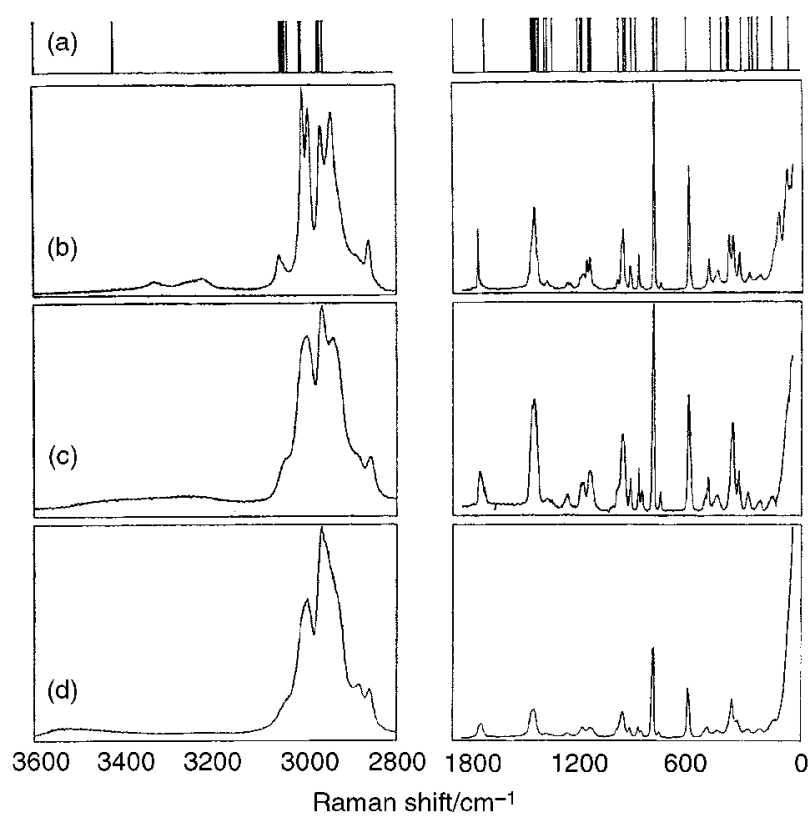

Fig. 4 Raman spectra of methyl $\alpha$-hydroxy-isobutyrate. (a) CFF95 calculated spectrum (since intensities are not predicted by the calculations, the spectrum is shown schematically); (b) crystal $(T=233 \mathrm{~K})$; (c) glassy state $(T=123 \mathrm{~K})$ and $(\mathrm{d})$ liquid $(T=298 \mathrm{~K})$. 
Table 1 Experimental (Ar matrix) and calculated (ab initio HF/6-31G* and MM/CFF95) IR vibrational spectra of methyl $\alpha$-hydroxy-isobutyrate $^{a}$

\begin{tabular}{|c|c|c|c|c|c|c|c|}
\hline \multirow{4}{*}{$\begin{array}{l}\text { Approximate } \\
\text { description }\end{array}$} & \multirow{2}{*}{\multicolumn{7}{|c|}{$\begin{array}{l}\text { Conformer Syn-syn s-cis (point group: } C_{\mathrm{s}} \text { ) } \\
\text { Experimental } \\
\text { Calculated }\end{array}$}} \\
\hline & & & & & & & \\
\hline & \multicolumn{2}{|l|}{ MI-IR } & \multicolumn{2}{|c|}{$A b$ initio $\mathrm{HF} / 6-31 \mathrm{G}^{*}$} & \multicolumn{3}{|l|}{ MM/CFF95 } \\
\hline & $v_{\text {exp }} / \mathrm{cm}^{-1}$ & $I_{\exp }^{b}$ & $v_{\mathrm{HF}} / \mathrm{cm}^{-1}$ & $I_{\mathrm{HF}}^{c}$ & $v_{\mathrm{CFF} 95} / \mathrm{cm}^{-1}$ & $I_{\mathrm{CFF} 95^{d}}$ & $\Delta v / \mathrm{cm}^{-1 e}$ \\
\hline vOH & 3545 & 77 & 3633 & 110 & 3589 & 213 & -44 \\
\hline $\mathrm{vOCH}_{3}$ as.' & 3047 & 2 & 3002 & 23 & 2987 & 32 & 60 \\
\hline $\mathrm{vOCH}_{3}$ as." & 3038 & 4 & 2986 & 27 & 2979 & 36 & 59 \\
\hline $\mathrm{vCH}_{3}$ as.'(1) & 3014 & 10 & 2959 & 44 & 2957 & 7 & 57 \\
\hline $\mathrm{vCH}_{3}$ as."(1) & 3002 & 6 & 2951 & 6 & 2949 & 22 & 53 \\
\hline $\mathrm{vCH}_{3}$ as.'(2) & 2996 & 12 & 2942 & 36 & 2958 & 65 & 38 \\
\hline $\mathrm{vCH}_{3}$ as."(2) & 2993 & 26 & 2938 & 23 & 2952 & 70 & 41 \\
\hline $\mathrm{vOCH}_{3}$ s. & 2966 & 27 & 2911 & 35 & 2896 & 8 & 70 \\
\hline $\mathrm{vCH}_{3}$ s.(2) & 2955 & 4 & 2882 & 9 & 2886 & 18 & 69 \\
\hline $\mathrm{vCH}_{3}$ s.(1) & 2945 & 6 & 2876 & 29 & 2885 & 7 & 59 \\
\hline$v \mathrm{C}=\mathrm{O}$ & 1740 & 259 & 1778 & 302 & 1739 & 68 & 1 \\
\hline$\delta \mathrm{CH}_{3}$ as.'(2) & 1470 & 24 & 1481 & 15 & 1466 & 11 & 4 \\
\hline$\delta \mathrm{CH}_{3}$ as."(2) & $\int 1464 f$ & 26 & 1473 & 9 & 1494 & 21 & -30 \\
\hline $\mathrm{\delta OCH}_{3}$ as.' & $1464^{\prime}$ & 6 & 1471 & 2 & 1469 & 8 & -5 \\
\hline$\delta \mathrm{OCH}_{3}$ as." & 1449 & 8 & 1467 & 5 & 1446 & 19 & 3 \\
\hline$\delta \mathrm{OCH}_{3}$ s. & & 14 & 1458 & 3 & 1427 & 29 & 14 \\
\hline$\delta \mathrm{CH}_{3}$ as."(1) & $\left\{1441^{f}\right.$ & 9 & 1456 & 2 & 1465 & 22 & -25 \\
\hline$\delta \mathrm{CH}_{3}$ as.'(1) & & 1 & 1453 & $<1$ & 1470 & 12 & -29 \\
\hline $\mathrm{\delta CH}_{3}$ s.(2) & 1383 & 12 & 1405 & 10 & 1429 & 94 & -45 \\
\hline$\delta \mathrm{COH}$ & 1373 & 8 & 1391 & 3 & 1352 & 36 & 21 \\
\hline$\delta \mathrm{CH}_{3}$ s. $(1)$ & 1362 & 8 & 1385 & 3 & 1428 & 104 & -65 \\
\hline$v \mathrm{C}-\mathrm{O}$ & 1261 & 259 & 1282 & 358 & 1388 & 51 & -127 \\
\hline$v \mathrm{C}-\mathrm{O}(\mathrm{H})$ & 1196 & 398 & 1222 & 348 & 1261 & 242 & -65 \\
\hline$\rho \mathrm{OCH}_{3}^{\prime}$ & 1189 & 103 & 1197 & 24 & 1140 & 7 & 49 \\
\hline $\mathrm{vCC}$ as. & 1186 & 96 & 1176 & 31 & 1242 & 2 & -56 \\
\hline$\rho \mathrm{OCH}_{3}^{\prime \prime}$ & 1163 & 8 & 1159 & 4 & 1123 & 4 & 40 \\
\hline$\rho \mathrm{CH}_{3}^{\prime}(1)$ & 1146 & 40 & 1147 & 29 & 940 & 24 & 206 \\
\hline$\rho \mathrm{CH}_{3}^{\prime \prime}(1)$ & 994 & 3 & 1005 & 1 & 996 & $<1$ & -2 \\
\hline $\mathrm{vO}-\mathrm{C}\left(\mathrm{H}_{3}\right)$ & 986 & 29 & 996 & 39 & 1019 & 18 & -33 \\
\hline$\rho \mathrm{CH}_{3}^{\prime}(2)$ & 978 & 52 & 985 & 38 & 939 & 6 & 39 \\
\hline$\rho \mathrm{CH}_{3}^{\prime \prime}(2)$ & n.o. & n.o. & 916 & $<1$ & 1163 & 44 & $(-247)$ \\
\hline$v C C$ & 893 & 16 & 884 & 4 & 872 & 17 & 21 \\
\hline$v \mathrm{CC} \mathrm{s}$. & 789 & 39 & 789 & 8 & 776 & $<1$ & 13 \\
\hline$\rho C=O$ & 771 & 28 & 763 & 21 & 812 & 65 & -41 \\
\hline$\delta \mathrm{O}=\mathrm{C}-\mathrm{O}$ & 614 & 13 & 589 & 13 & 592 & 13 & 22 \\
\hline$\delta C C=O$ & 475 & 2 & 484 & 4 & 425 & 18 & 50 \\
\hline$\rho \mathrm{C}\left(\mathrm{CH}_{3}\right)_{2}$ & 415 & 2 & 421 & 2 & 386 & 5 & 29 \\
\hline$\delta \mathrm{OCC}$ & n.i. & n.i. & 370 & 27 & 364 & 21 & (6) \\
\hline$\omega \mathrm{C}\left(\mathrm{CH}_{3}\right)_{2}$ & n.i. & n.i. & 336 & 4 & 319 & 3 & (17) \\
\hline$\delta \mathrm{C}\left(\mathrm{CH}_{3}\right)_{2}$ & n.i. & n.i. & 303 & 7 & 289 & 20 & (14) \\
\hline$\tau \mathrm{C}-\mathrm{O}(\mathrm{H})$ & n.i. & n.i. & 286 & 97 & 201 & 121 & (165) \\
\hline$\tau \mathrm{C}-\mathrm{C}$ as. & n.i. & n.i. & 256 & $<1$ & 236 & 24 & (20) \\
\hline tw $\mathrm{C}\left(\mathrm{CH}_{3}\right)_{2}$ & n.i. & n.i. & 241 & 12 & 278 & 51 & $(-37)$ \\
\hline$\tau \mathrm{C}-\mathrm{C} \mathrm{s}$ & n.i. & n.i. & 219 & 2 & 248 & $<1$ & $(-29)$ \\
\hline$\delta \mathrm{COC}$ & n.i. & n.i. & 189 & 1 & 199 & 70 & $(-10)$ \\
\hline$\tau \mathrm{O}-\mathrm{C}\left(\mathrm{H}_{3}\right)$ & n.i. & n.i. & 149 & 2 & 156 & 31 & $(-7)$ \\
\hline$\tau \mathrm{C}-\mathrm{O}$ & n.i. & n.i. & 112 & 4 & 135 & 18 & $(-23)$ \\
\hline$\tau \mathrm{C}-\mathrm{C}$ & n.i. & n.i. & 21 & 4 & 48 & $<1$ & $(-27)$ \\
\hline
\end{tabular}

${ }^{a}$ Wavenumbers in $\mathrm{cm}^{-1} ; v$, stretching; $\delta$, bending; $\omega$, wagging; tw, twisting; $\rho$, rocking; $\tau$, torsion, s., symmetric; as., asymmetric; n.i., not investigated; n.o., not observed; (1), $\mathrm{CH}_{3}$ groups in phase; (2), $\mathrm{CH}_{3}$ groups out-of-phase. ${ }^{b} \mathrm{MI}-\mathrm{IR}$ intensities were normalized to the total calculated intensities of the bands which have an experimental counterpart by using the formula $I_{(\mathrm{i})^{\exp }} I_{(\mathrm{i}) \text { obs }} \times \Sigma_{j-1, n} I_{(1)}^{\mathrm{HF}} / \Sigma_{j-1, n} I_{(\mathrm{i})^{\text {obs }}}$, where the sums extend to all bands observed. ${ }^{c}$ Calculated IR intensities in $\mathrm{km} \mathrm{mol}{ }^{-1}{ }^{d} \mathrm{MM} / \mathrm{CFF} 95$ intensities were normalized to the $a b$ initio $\mathrm{HF} / 6$ $31 \mathrm{G}^{*} .{ }^{e} \Delta v=v_{\exp }-v_{\mathrm{CFF} 95}$ (values in brackets are from $\Delta v=v_{\mathrm{HF}}-v_{\mathrm{CFF} 95}$ ). ${ }^{f}$ Experimental intensities of the component bands were estimated by dividing the total observed intensity in agreement with their calculated intensity ratios.

In the IR experiments, the method used to prepare the sample was completely different, as described in the Experimental section: the $\mathrm{KBr}$ substrate was first cooled to $13 \mathrm{~K}$ under high vacuum and then MHib vapour was sprayed onto the cold window. As could be expected, the thin film formed in this way exhibits a glassy state structure, clearly reflected in its IR spectrum (see Fig. 3). Upon increasing the temperature no significant changes in the IR spectrum that could be correlated with a phase transition until evaporation of the film occurs were observed. Very unfortunately, under these experimental conditions, evaporation of the sample at the temperature at which the crystal formation could be expected to occur $(c a .213 \mathrm{~K})$ is practically complete, so this phase cannot be studied in this way.

In order to identify the most important intermolecular interactions between MHib molecules, which are essential to characterize the structure of the crystalline phase, a systematic search on the CFF95 potential energy surface of the dimer was undertaken. In agreement with the experimental evidence, monomeric units were considered to assume a nearly Ss conformation. It is here assumed that the dimer should constitute the basic structural associate within the crystalline unit cells. The most stable dimeric structures found are shown in Fig. 5. The two lowest energy associates $\left(\mathrm{D}^{\mathrm{I}}\right.$ and $\mathrm{D}^{\mathrm{II}}$, belonging to the 


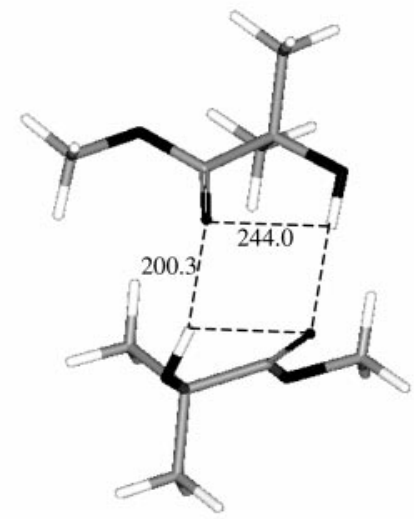

$\mathrm{D}^{\mathrm{I}}$

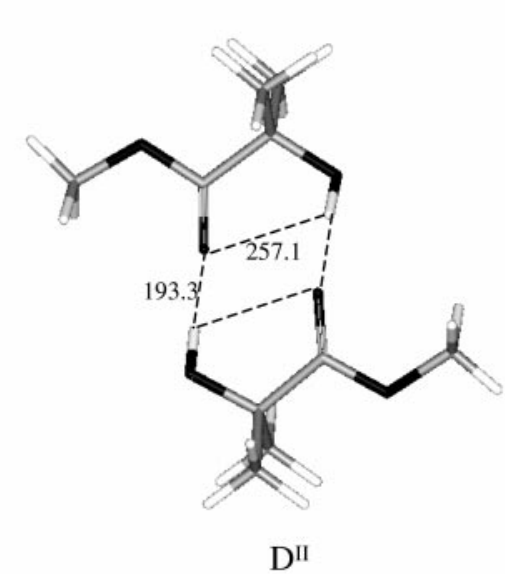

$\Delta E_{\left(\mathrm{D}^{\mathrm{II}}{ }_{\mathrm{D}} \mathrm{I}\right)}=1.72 \mathrm{~kJ} \mathrm{~mol}^{-1}$

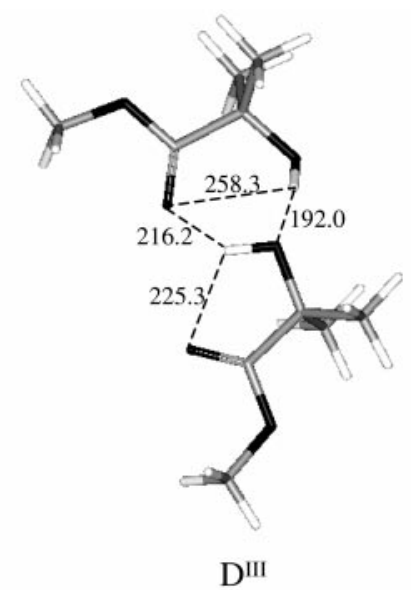

$\Delta E_{\left(\mathrm{D}^{\mathrm{III}}{ }_{-\mathrm{D}} \mathrm{I}_{3}\right.}=8.37 \mathrm{~kJ} \mathrm{~mol}^{-1}$

Fig. 5 Most stable dimers of methyl $\alpha$-hydroxy-isobutyrate. Calculated hydrogen bond distances in pm.

$C_{2}$ and $C_{1}$ symmetry point groups, respectively) have an inversion centre in the middle of the ten-atom ring resulting from the establishment of two equivalent $\mathrm{OH} \cdots \mathrm{O}^{\prime}=\mathrm{C}$ intermolecular hydrogen bonds between the hydroxy group of one molecule and the carbonyl oxygen atom of the second molecule. These dimers are predicted to have very similar energies, with $\Delta E_{\mathrm{DII}-\mathrm{DI}}=1.72 \mathrm{~kJ} \mathrm{~mol}^{-1}$. The highest energy form $\left(\mathbf{D}^{\text {III }} ; \Delta E_{\mathbf{D} \text { III }-\mathbf{D}^{\mathrm{I}}}=8.37 \mathrm{~kJ} \mathrm{~mol}^{-1}\right.$ ) exhibits an eight-atom ring and belongs to the $C_{1}$ point group, showing non-equivalent $\mathrm{OH}$ and $\mathrm{C}=\mathrm{O}$ groups.

Once the structures of the most stable dimers were obtained, simulation of crystalline phases based on these dimers was undertaken. Full optimization of periodic structures based on the three dimeric structures found was systematically done and the calculated spectra compared with the observed data. All fundamental lattice parameters (axes and angles) were let free to vary independently during the optimization process, the most stable structures found belonging to the space group $P_{1}$. Amongst all the periodic structures studied, the most stable one was found to be based on $\mathbf{D}^{\mathrm{II}}$, being more stable than the most stable periodic structures based on $\mathbf{D}^{\mathrm{I}}$ or $\mathbf{D}^{\mathrm{III}}$ by more than $15 \mathrm{~kJ} \mathrm{~mol}^{-1}$. In this structure, the two equivalent-by-symmetry molecules of MHib that form the basic dimeric unit assume nearly Ss conformations with an intramolecular $\mathrm{OH} \cdots \mathrm{O}=\mathrm{C}$ hydrogen bond $[d(\mathrm{OH} \cdots \mathrm{O}=\mathrm{C})=257.2 \mathrm{pm}]$, and are connected by relatively stronger intermolecular $\mathrm{OH} \cdots \mathrm{O}^{\prime}=\mathrm{C}$ hydrogen bonds $\left[d\left(\mathrm{OH}^{\prime} \cdots \mathrm{O}^{\prime}=\mathrm{C}\right)=193.3 \mathrm{pm}\right]$. The calculated vibrational data for this periodic structure are shown in Fig. 4 and, as can be noticed, agree quite well with the experimental results. It is worth noting that the calculated vibrational spectra obtained for other periodic structures of relatively low energy, in particular the most stable structures based on $\mathbf{D}^{\mathrm{I}}$ and $\mathbf{D}^{\mathrm{III}}$, do not fit so well to the experimental data. For instance, for the most stable periodic structure, the absolute error between the calculated and experimental vibrational frequencies for those modes associated with the groups which are directly involved in hydrogen bonding is $c a .20 \mathrm{~cm}^{-1}$ whereas the minimum errors for $\mathbf{D}^{\mathrm{I}}$ and $\mathbf{D}^{\mathrm{II}}$-based periodic structures were found to be approximately 35 and $70 \mathrm{~cm}^{-1}$, respectively. Hence, despite the simplicity of the model used here to simulate the observed crystalline phase of MHib, it can be concluded that with all probability this is based on $\mathbf{D}^{\text {II }}$.

Considering the good general agreement between the calculated and experimental vibrational frequencies now obtained and the general discussion of the liquid phase and matrix isolation spectra of MHib we presented elsewhere, ${ }^{8}$ a detailed analysis of the assignments made here does not seem neces- sary. However, some specific spectral regions deserve further comments.

OH stretching ( $\mathrm{VOH})$ region. As is usual for hydroxylcontaining molecules participating in $\mathrm{H}$-bonding, bands due to $\mathrm{vOH}$ appear as very broad features, which are very intense in the IR spectrum and much weaker in the Raman spectrum. In the liquid both Ss and Gsk conformers were found to exist $\left(\Delta E_{\mathrm{Gsk}-\mathrm{Ss}}=3.4 \mathrm{~kJ} \mathrm{~mol}^{-1}\right) .^{8}$ Increasing the temperature leads to an increase in the high frequency side of the $\mathrm{vOH}$ IR band (which has a maximum at $3491 \mathrm{~cm}^{-1}$ ), in agreement with an increase in the population of the less stable conformer Gsk, where this vibration occurs at a higher frequency than in the most stable conformer. ${ }^{8}$ In the glassy state, two broad overlapping bands are ascribed to $\mathrm{vOH}$. These bands can be attributed to different types of aggregates to which monomeric structures similar to both Ss and Gsk conformers may contribute, and appear at considerably lower frequencies $(3423$ and $3256 \mathrm{~cm}^{-1}$ ) than in the liquid, indicating that $\mathrm{H}$-bonding is considerably more efficient in the glassy state than in the liquid phase. As could be expected, in the Raman spectra of the crystal, the bands due to $\mathrm{vOH}$ are observed at even lower frequencies than in the glass $\left(3331\right.$ and $3221 \mathrm{~cm}^{-1}$, the last band showing a shoulder at $c a .3257 \mathrm{~cm}^{-1}$ ). The origin of the bands observed in the $\mathrm{vOH}$ region of the spectrum of the crystal is still not completely understood. Though Fermi resonance between the Raman active $\mathrm{vOH}$ fundamentals and the first overtones of the carbonyl stretching modes can contribute to the observed splitting, ${ }^{8}$ it is more probable that at least the most intense bands are due to the presence in the crystal of different dimeric structures based on $\mathbf{D}^{\mathrm{II}}$ but occupying non-equivalent positions in the crystal unit cell. A detailed assignment of these bands would then require precise knowledge of the crystal structure, which is, however, beyond the scope of this study.

$\mathrm{CO}$ stretching and $\mathrm{COH}$ bending vibrations $[v \mathrm{C}=\mathrm{O}, v \mathrm{C}-\mathrm{O}$, $\left.\mathbf{v C}-\mathbf{O}(\mathbf{H}), \quad v \mathbf{O}-\mathbf{C}\left(\mathbf{H}_{3}\right), \quad \delta \mathbf{C O H}, \tau \mathbf{C}-\mathbf{O}(\mathbf{H})\right]$. The carbonyl stretching vibrations could be assigned easily in all spectra since they lie in a relatively clear spectral region. In both liquid and glassy states, two overlapping bands resulting from the $v \mathrm{C}=\mathrm{O}$ vibrations of the two conformers were observed [IR data, presented as (Gsk; Ss): liquid $\left(1758,1735 \mathrm{~cm}^{-1}\right)$; glassy state $\left.\left(1746,1732 \mathrm{~cm}^{-1}\right)\right]$. In the spectra of the crystal this mode is assigned to the band appearing at $1762 \mathrm{~cm}^{-1}$, in fairly good agreement with the calculated value $\left(1731 \mathrm{~cm}^{-1}\right)$. The small band observed at $1751 \mathrm{~cm}^{-1}$ is tentatively assigned to the combination band $v \mathrm{C}-\mathrm{C} \mathrm{s}+\rho \mathrm{CH}_{3}^{\prime}(2)$, which may be 
interacting by Fermi resonance with the carbonyl stretching fundamental (this interaction may justify the fact that $\mathrm{vC}=\mathrm{O}$ appears blue shifted in the crystal when compared with both the liquid and glassy states).

The remaining three $\mathrm{CO}$ stretching vibrations, $\mathrm{vC}-\mathrm{O}$, $v \mathrm{C}-\mathrm{O}(\mathrm{H})$ and $v \mathrm{O}-\mathrm{C}\left(\mathrm{H}_{3}\right)$ are predicted to occur in the crystalline phase near 1233, 1217 and $968 \mathrm{~cm}^{-1}$, respectively, and are ascribed to the bands observed at 1291, 1221 and 997/987 $\mathrm{cm}^{-1}$. In the case of $\mathrm{vO}-\mathrm{C}\left(\mathrm{H}_{3}\right)$, the observed doublet may have the same origin as described above for $v \mathrm{O}-\mathrm{H}$. In the liquid and in the glassy state these bands appear at 1278, 1193 (overlapped with $\rho \mathrm{OCH}_{3}^{\prime}$ ) and $978 \mathrm{~cm}^{-1}$ and 1288, 1209 and $984 \mathrm{~cm}^{-1}$, respectively (IR data). Due to the fact that the methyl ester group does not take any active role in intermolecular hydrogen bonding, $\mathrm{vO}-\mathrm{C}\left(\mathrm{H}_{3}\right)$ appears nearly at the same frequency in the condensed phases and for the isolated molecule [Ss: 986 (IR; gas), 978/985 (IR/Raman; liquid), 984/992 (IR/Raman; glassy state), 997 and 987 (Raman doublet; crystal); Gsk: 1029 (IR; gas), 1031 (Raman; glassy state)]. On the other hand, $v \mathrm{C}-\mathrm{O}$ and $v \mathrm{C}-\mathrm{O}(\mathrm{H})$ exhibit relatively important blue shifts when compared with the isolated molecule situation (1261 and $1196 \mathrm{~cm}^{-1}$, respectively). ${ }^{8} \S$ It is worth mentioning that $\mathrm{vC}-\mathrm{O}$ has been suggested to be a good probe of the local polarity around the carboxylic ester group, enabling one to estimate the relative strengths of hydrogen bonding in different experimental conditions. ${ }^{7}$ A higher $\mathrm{vC}-\mathrm{O}$ frequency correlates with a more polar environment and a more extensive involvement of the carboxylic ester group in hydrogen bonding. ${ }^{7}$ As expected, for MHib, vC-O increases in the order: isolated molecule $\left(1261 \mathrm{~cm}^{-1}\right)<$ liquid $(1278$ $\left.\mathrm{cm}^{-1}\right)<$ glassy state $\left(1288 \mathrm{~cm}^{-1}\right)<\operatorname{crystal}\left(1291 \mathrm{~cm}^{-1}\right)$.

Intermolecular hydrogen bonding has also important consequences regarding the frequencies of the $\mathrm{COH}$ bending vibrations. In the isolated MHib molecule, $\delta \mathrm{COH}$ is observed at $1373 \mathrm{~cm}^{-1}$ and $\tau \mathrm{C}-\mathrm{O}(\mathrm{H})$ was predicted to occur at $c a .286$ $\mathrm{cm}^{-1}$ (scaled ab initio $6-31 \mathrm{G}^{*}$ value). ${ }^{8}$ In the crystalline state, $\delta \mathrm{COH}$ appears at a considerably higher frequency (1404 $\mathrm{cm}^{-1}$ ) while $\tau \mathrm{C}-\mathrm{O}(\mathrm{H})$ was predicted to occur at $c a .812 \mathrm{~cm}^{-1}$, following the trend previously observed for other hydroxylic molecules ${ }^{7,20}$ and in agreement with the expected increase in

$\S$ In the case of $\mathrm{vC}-\mathrm{O}(\mathrm{H})$, data for the liquid cannot be used in this correlation due to extensive overlap with the band due to $\mathrm{\rho OCH}_{3}^{\prime}$. the force constants associated with these vibrations due to a stronger involvement of the hydroxy groups in hydrogen bonding.

\section{Acknowledgements}

The authors acknowledge Dr. João Cecílio for his technical help and Fundação para a Ciência e a Tecnologia (FCT), Lisbon, for financial support (research project PRAXIS QUI/ 10137/98). Susana Jarmelo acknowledges the M.Sc. Grant (ref. SFRH/157/2000) from FCT.

\section{References}

1 E. V. Scott, J. Am. Acad. Derm., 1984, 11, 867.

2 Y. Guzel, J. Mol. Struct. (Theochem.), 1996, 366, 131.

3 L. Moy, H. Murad and R. L. Moy, J. Derm. Surg. Oncol., 1996, 19, 243.

4 E. V. Scott, Can. J. Derm., 1989, 43, 222.

5 B. S. Kim and D. J. Mooney, Trends Biotechnol., 1998, 16, 224

6 T. Rezanka, J. Reichelova and J. Kopecky, FEMS Microbiol. Lett., 1991, 84, 33.

7 S. Jarmelo, T. M. R. Maria, M. L. P. Leitão and R. Fausto, Phys. Chem. Chem.Phys., 2000, 2, 1155.

8 S. Jarmelo and R. Fausto, J. Mol. Struct., 1999, 509, 183.

9 F. A. Miller and B. M. Harney, Appl. Spectrosc., 1970, 2, 291.

10 R. Sabbah, A. Xu-Wu, J. S. Chickos, M. L. P. Leitão, M. V. Roux and L. A. Torres, Thermochim. Acta, 1999, 331, 93.

11 A.T. Hagler and C. S. Ewig, Comput. Phys. Commun., 1994, 84 131; M. J. Hwang, T. P. Stockfish and A. T. Hagler, J. Am. Chem. Soc., 1994, 116, 2515.

12 Cerius2 (Version 3.5), Molecular Simulations Inc., San Diego, CA, 1997.

13 J. C. C. Lage, PhD Thesis, University of Coimbra, Portugal, 1999.

14 M. R. Richardson and N. G. Savill, Polymer, 1975, 16, 753.

15 M. J. Richardson, Plast. Rubber Mater. Appl., 1976, 1, 162.

16 U. Burket and N. L. Allinger, Molecular Mechanics, ACS Monograph 177, American Chemical Society, Washington, DC, 1982.

17 A. Soldera and J. P. Dognon, Macromol. Symp., 1997, 119, 157.

18 R. Fausto, Rev. Port. Quím., 1996, 3, 59.

19 K. Rasmussen, Potential Energy Functions in Conformational Analysis, Lecture Notes in Chemistry, Springer-Verlag, Heidelberg, 1985, vol. 37.

20 R. Fausto, J. Mol. Struct., 1996, 377, 181. 